\title{
Transversalidade e ensino: o que falta para ser realidade?
}

\author{
Érica P. Conde
}

Universidade Federal do Piauí - UFPI

\begin{abstract}
Resumo
A transversalidade permite que a educação seja interdisciplinar, mas o que percebemos são professores temerosos por invadir assuntos referentes à outra área. Falta uma educação crítica direcionada ao aluno, na qual a curiosidade seja o ponto de partida e a participação, a chegada. Do outro lado, precisamos de professores que estejam aptos a refletir sobre o fazer constante em sala de aula.
\end{abstract}

Palavras-chave: Transversalidade, Interdisciplinaridade, Ensino.

\begin{abstract}
Transversality allows education to be interdisciplinary, but what we observe is that teachers are reluctant to teach topics from other disciplinary areas. There is a lack of a critical education directed to the student, in which curiosity is the starting point and participation is the goal. At the same time, we need teachers who are able to reflect on their everyday practice in the classroom.
\end{abstract}

Key-words: Transversality, Interdisciplinarity, Education.

\section{INTRODUÇÃO}

O professor, em sala de aula, é responsável pela formação de pessoas. Partindo desse enfoque, podemos dizer que a educação vai além dos conteúdos ministrados. No que se refere a temas transversais, a grande questão a ser discutida é o fato de professores de algumas disciplinas, Ciências, História, Geografia, por exemplo, acharem-se exclusivamente capazes de comentar assuntos como saúde, ética e pluralidade cultural, ou seja, consideram-se os únicos competentes para fazerem uma discussão sobre essas temáticas.

De certa forma, não tiramos o mérito dessas questões das disciplinas específicas. No entanto, acreditamos que os temas transversais, inseridos nos Parâmetros Curriculares Nacionais (PCN) trazem a possibilidade de temas como ética, meio ambiente, sexo, além de outros, serem enfatizados em qualquer disciplina. 
Assim, nossa proposta consiste em discutir o porquê de os professores de diferentes disciplinas poderem tratar de temas que envolvem questões de interesse comum. Partimos do pressuposto de que não deve haver omissões em relação a temáticas sociais que podem permear os assuntos tratados por professores em suas aulas ou serem colocados por alunos de acordo com seus interesses e até afinidades com o ministrante de uma disciplina específica.

Garcia [s.d., s.p], ao discorrer sobre a transversalidade, faz um trabalho que une esse tema com a interdisciplinaridade, pois afirma serem os temas transversais pontos de convergências entre os saberes:

\begin{abstract}
Existem temas cujo estudo exige uma abordagem particularmente ampla e diversificada. Alguns deles foram inseridos nos parâmetros curriculares nacionais, que os denomina Temas Transversais e os caracteriza como temas que "tratam de processos que estão sendo intensamente vividos pela sociedade, pelas comunidades, pelas famílias, pelos alunos e educadores em seu cotidiano. São debatidos em diferentes espaços sociais, em busca de soluções e de alternativas, confrontando posicionamentos diversos tanto em relação à intervenção no âmbito social mais amplo quanto à atuação pessoal. São questões urgentes que interrogam sobre a vida humana, sobre a realidade que está sendo construída e que demandam transformações macrossociais e também de atitudes pessoais, exigindo, portanto, ensino e aprendizagem de conteúdos relativos a essas duas dimensões" (PCN). Estes temas envolvem um aprender sobre a realidade, na realidade e da realidade, destinando-se também a um intervir na realidade para transformá-la. Outra de suas características é que abrem espaço para saberes extra-escolares. Na verdade, os temas transversais prestam-se de modo muito especial para levar à prática a concepção de formação integral da pessoa.
\end{abstract}

O que Garcia [s.d., s.p.] propõe consiste em desconsiderar as fragmentações de conhecimentos a partir dos temas transversais, visto que eles permeiam toda a prática educativa, exigindo "um trabalho sistemático, contínuo, abrangente e integrado no decorrer de toda a educação".

Os PCN também estabelecem aproximações entre a transversalidade e a interdisciplinaridade:

A interdisciplinaridade questiona a segmentação entre os diferentes campos de conhecimento produzidos por uma abordagem que não leva em conta a inter-relação e a influência entre eles - questiona a visão compartimentada (disciplinar) da realidade sobre a qual a escola, tal como é conhecida, historicamente se constituiu. A transversalidade diz respeito à possibilidade de se estabelecer, na prática educativa, uma relação entre aprender conhecimentos teoricamente sistematizados (aprender sobre a realidade) e as questões da vida real e de sua transformação (aprender na realidade e da realidade). E a uma forma de sistematizar esse trabalho e incluí-lo explícita e estruturalmente na organização curricular, garantindo sua continuidade e aprofundamento ao longo da escolaridade. (BRASIL, 1998:30) 
Pelo exposto, podemos dizer que a transversalidade surge nos PCN com o intuito de viabilizar o uso da interdisciplinaridade, visto que, como já expusemos, os temas transversais aproximam as disciplinas. Assim, não há como dizer que a interdisciplinaridade está longe de se tornar realidade. O que de fato falta é começarmos a criar situações de uso dessa possibilidade no âmbito escolar.

Acreditamos que o começo de um bom trabalho com os temas transversais dá-se, inicialmente, com a busca da educação crítica. O sentido do aprendizado só é atingido a partir do momento em que o aluno é envolvido na construção do saber formalizado. A criticidade deve ser estimulada a partir de questionamentos, independente de qualquer disciplina existente em uma grade curricular, em relação aos temas transversais.

O ser crítico é valorizado por Freire (1999) ao mostrar a necessidade de o aluno inquietar-se diante do desconhecido. Ser curioso surge como ponto de partida para novas descobertas.

A curiosidade como inquietação indagadora, como inclinação ao desvelamento de algo, como pergunta verbalizada ou não, como procura de esclarecimento, como sinal de atenção que sugere e alerta faz parte integrante do fenômeno vital. Não haveria criatividade sem a curiosidade que nos move e que nos põe pacientemente impacientes diante do mundo que não fizemos, acrescentando a ele algo que fazemos. (FREIRE, 1999:35)

Em outras palavras, curiosidade e criticidade estão bem próximas na visão freiriana: a primeira pode ser vista como o ponto inicial para a adquirição de um conhecimento; a segunda, sem prescindir da primeira, apresenta-se como consequência, resultado.

Não há ainda como falar de criticidade, sem falar de ética. Aqui a palavra ética indica respeito, consideração, reconhecimento do que é feito pelo outro. Assim, a ética dá respaldo à curiosidade, limitando-a. A ética, no sentido de ser capaz de produzir e respeitar essa produção, é outro aspecto defendido por Freire (1999):

Uma crítica permanente aos desvios fáceis com que somos tentados, às vezes ou quase sempre, a deixar dificuldades que os caminhos verdadeiros podem nos colocar. Mulheres e homens, seres histórico-sociais, nos tornamos capazes de comparar, de valorar, de intervir, de escolher, de decidir, de romper, por tudo isso, nos fizemos seres éticos. Só somos, porque estamos sendo. Estar sendo é a condição, entre nós, para ser. Não é possível pensar os seres humanos longe, sequer, da ética, 
quanto mais fora dela. Estar longe ou pior, fora da ética, entre nós, mulheres e homens, é uma transgressão. (FREIRE, 1999:36 - 37)

É perfeitamente compreensível perceber, após a leitura de Freire (1999), o caminho da educação crítica: curiosidade - criticidade - ética. Entretanto, a concretização desse percurso é o exemplo.

Esse é outro ponto bem controverso: a questão do exemplo. O exemplo sustenta o discurso, segundo Freire (1999). Não há criticidade sem prática:

\begin{abstract}
Não há como pensar certo fora de uma prática testemunhal que o re-diz em lugar de desdizê-lo. Não é possível ao professor pensar que pensa certo, mas, ao mesmo tempo, pergunta ao aluno se ele sabe "com quem está falando".

O clima de quem pensa certo é o de quem busca seriamente a segurança na argumentação, é o de quem, discordando do seu oponente, não tem por que contra ele ou contra ela nutrir uma raiva desmedida, bem maior, as vezes, do que a razão mesma da discordância. Uma dessas pessoas desmedidamente raivosas proibiu, certa vez, de um estudante que trabalhava dissertação sobre alfabetização e cidadania que me lesse. "Já era", disse com ares de quem trata com rigor e neutralidade o objeto, que era eu. "Qualquer leitura que você faça deste senhor pode prejudicá-lo". Não é assim que se pensa certo nem é a assim que se ensina certo. Faz parte do pensar certo o gosto da generosidade que, não negando a quem o tem o direito à raiva, a distingue da raivosidade irrefreada. (FREIRE, 1999:38-39)
\end{abstract}

Pelo exposto, percebemos que fazer uma prática pedagógica, fundamentada pela criticidade, sem a prática, o exemplo, como suporte do que é dito, cria uma educação sem sentido de existir. Dessa maneira, não podemos valorar o discurso em detrimento do exemplo, mas fazer com que um justifique o outro. Isso é de fundamental importância para entender a transversalidade.

A criticidade, partindo do princípio que pode ser construída, concretiza-se perante o outro. Então, aqui, podemos falar do papel dos professores nessa questão. Estaríamos diante de uma reflexão quanto à importância dos temas transversais no contexto escolar, a fim de viabilizar a existência da visão crítica de nossos alunos.

Ensinar a questionar, a ter respeito perante os outros, ter consciência de nossos direitos e deveres refere-se ao termo criticidade. Exercitá-la já se torna bem mais trabalhoso, pois requer empenho, participação e, principalmente o querer fazer, o que há pouco chamamos de exemplo, tendo por base os ensinamentos de Freire (1999). Desse modo, parece-nos que os aspectos referentes à criticidade ficam, apenas, na teoria, pois mobilizar a escola para "fazer" requer preparação e envolvimento de todos. 
A participação que aqui defendemos é uma participação efetiva e também política, no sentido de dar voz ao aluno em sala de aula. A transversalidade, acreditamos, possibilita o desenvolvimento da criticidade, mas para que isso se concretize, precisamos de professores mediadores e alunos sujeitos do processo ensinoaprendizagem.

A concretização da criticidade dá-se, dessa forma, com a efetiva participação. Encontramos, então, a educação política, tendo como ponto de partida não apenas os conteúdos formais, mas, principalmente, os assuntos pertinentes ao nosso dia a dia.

Outro aspecto que não podemos esquecer é o fato de essa participação depender da forma como as pessoas percebem os valores. Valores como a aceitação de culturas diferentes, atitudes perante a democracia, o poder de gerir, o uso do bem comum. Alguns desses comportamentos estão extintos. $\mathrm{O}$ grande desafio das escolas consiste em começar a identificar a maneira como as pessoas percebem os valores.

Para que isso se efetive na prática, discussões que envolvam normas, crenças e valores devem ser retomadas na escola. Já que as disciplinas encarregadas pelos estudos da cultura e da política não comportam em sua carga horária ampla discussão, cabem, então, projetos interdisciplinares, trabalhos com assuntos complementares e comuns e, por que não a inclusão de textos com temáticas distintas nas aulas de português?

A fim de realizarmos um trabalho bem fundamentado em sala de aula sobre a investigação e até a discussão e construção de valores, normas e crenças, lembramos as possíveis maneiras de abordarmos os conteúdos inseridos nos temas transversais em sala de aula.

A educação envolve pilares, que podem ser resumidos nas várias formas de trabalharmos o ensino-aprendizado: factual (memorizar), conceitual (conhecer), procedimental (fazer) e atitudinal (ser e viver juntos), conforme nos instrui Coll (apud Zabala,1996).

Para Coll (apud Zabala,1996) pensar na forma de abordagem de conteúdos consiste em pensar na aprendizagem. O autor defende que o conteúdo factual é aquele que apresenta estratégias de aprendizagem simples, requer memorização; o conceitual, por sua vez, exige um trabalho cognoscitivo por parte do aprendiz, consiste no conhecimento de conceitos e princípios; o procedimental, por sua vez, está atrelado ao 
fazer, por isso podemos falar em ações; por fim, o atitudinal, o conhecimento de valores, normas e atitudes, envolve aspectos subjetivos que englobam os cognitivos, comportamentais e até afetivos.

Nosso enfoque é nos conteúdos atitudinais, os quais oportunizam um trabalho com a aprendizagem consciente. Viabilizam o uso dos temas transversais. Nesse ponto, acreditamos existir a possibilidade de realização de um trabalho voltado para temas como ética, meio ambiente, pluralidade cultural, dentre outros.

Que o professor é formador de opinião, não há dúvida. Dessa forma, não é possível abster-se de trabalhar com temas que podem transformar a realidade: ensinar educação no trânsito, abordar direitos e deveres, respeito ao próximo e às diferenças, dentre outros.

Gadott (1998), mais radicalmente, menciona que o professor precisa tomar partido, ou seja, engajar-se politicamente, estar a favor ou contra os oprimidos. Para ele, ao assumir-se politicamente, esse profissional pode usar a educação como um instrumento de luta, pois, através dela, cria-se a consciência crítica capaz de superar o senso comum.

Nessa mesma linha, Ruiz (2003) expõe que qualquer transformação só ocorre através do conhecimento. No caso do professor, precisa haver o conhecimento da realidade em que se inserem seus alunos:

Educadores e educadoras precisam engajar-se social e politicamente, percebendo as possibilidades da ação social e cultural na luta pela transformação das estruturas opressivas da sociedade classista. Para isso, antes de tudo necessitam conhecer a sociedade em que atuam e o nível social, econômico e cultural de seus alunos e alunas. (RUIZ, 2003:56)

Freire (1999:110), no entanto, diz ser o ato de educar uma outra forma de transformação:

Outro saber de que não posso duvidar um momento sequer na minha prática educativo-crítica é o de que, como experiência especificamente humana, a educação é uma forma de intervenção do mundo. Intervenção que além dos conhecimentos dos conteúdos bem ou mal ensinados e/ou aprendidos implica tanto o esforço de reprodução da ideologia dominante quanto o seu desmascaramento. Dialética e contraditória, não poderia ser a educação só uma ou só outra dessas coisas. Nem apenas reprodutora nem apenas desmascaradora da ideologia dominante. 
Com o exposto, vemos a relação entre conhecer e poder mudar. Isso pode ser direcionado para professores e alunos. No entanto, o grande desafio é começar a fazer sem temer interferências.

É preciso, pois, enfatizar que os PCN abordam os temas transversais, mostrando-os como uma possibilidade de os professores enfatizarem assuntos diversos em suas aulas; na verdade, nesse documento, esses temas estão abertos, dando flexibilidade aos currículos. Portanto, não é de competência, apenas, do professor de ciências, por exemplo, falar de assuntos como a preservação do meio ambiente.

\begin{abstract}
Os Parâmetros Curriculares Nacionais incorporam essa tendência e a incluem no currículo de forma a compor um conjunto articulado e aberto a novos temas, buscando um tratamento didático que contemple sua complexidade e sua dinâmica, dando-lhes a mesma importância das áreas convencionais. O currículo ganha em flexibilidade e abertura, uma vez que os temas podem ser priorizados e contextualizados de acordo com as diferentes realidades locais e regionais e outros temas podem ser incluídos.

O conjunto de temas aqui propostos (Ética, Meio Ambiente, Pluralidade Cultural, Saúde e Orientação Sexual) recebeu o título geral de Temas Transversais, indicando a metodologia proposta para sua inclusão no currículo e seu tratamento didático.

Esse trabalho requer uma reflexão ética como eixo norteador, por envolver posicionamentos e concepções a respeito de suas causas e efeitos, de sua dimensão histórica e política. (Brasil, 1998:25)
\end{abstract}

É preciso entender o que vem a ser transversalidade, para começar a perceber que diferentes áreas de conhecimentos podem fazer abordagens de assuntos diversos, por serem considerados como questões sociais. Os PCN colocam que temas transversais são temas complexos que permitem ser abordados por áreas diversas:

Por tratarem de questões sociais, os Temas Transversais têm natureza diferente das áreas convencionais. Sua complexidade faz com que nenhuma das áreas, isoladamente, seja suficiente para abordá-los. Ao contrário, a problemática dos Temas Transversais atravessa os diferentes campos do conhecimento. Por exemplo, a questão ambiental não é compreensível apenas a partir das contribuições da Geografia. Necessita de conhecimentos históricos, das Ciências Naturais, da Sociologia, da Demografia, da Economia, entre outros. Por outro lado, nas várias áreas do currículo escolar existem, implícita ou explicitamente, ensinamentos a respeito dos temas transversais, isto é, todas educam em relação a questões sociais por meio de suas concepções e dos valores que veiculam. No mesmo exemplo, ainda que a programação desenvolvida não se refira diretamente à questão ambiental e a escola não tenha nenhum trabalho nesse sentido, Geografia, História e Ciências Naturais sempre veiculam alguma concepção de ambiente e, nesse sentido, efetivam uma certa educação ambiental. (BRASIL, 1998:29)

O diálogo, fazendo parte da prática do professor, poderá abrir caminhos para o trabalho com os temas transversais, pois aproxima as diferenças, além de permitir a 
criação de novas posturas e, por que não dizer, para a construção de pessoas mais conscientes. Deveras, nesse tópico, podemos falar, mais uma vez, de Freire (1997) que afirma ser a educação um lugar para a elaboração coletiva e crítica da vida das pessoas, um lugar para a diversidade e diferença.

Um dos ensinamentos mais difundidos de Freire é a concepção de ensinar. Ensinar não é transmitir conhecimento:

\begin{abstract}
Saber que ensinar não é transferir conhecimento, mas criar as possibilidades para a sua própria produção ou a sua construção. Quando entro em uma sala de aula devo estar sendo um ser aberto a indagações, à curiosidade, às perguntas dos alunos, a suas inibições, um ser crítico e inquiridor, inquieto em face da tarefa que tenho - a ele ensinar e não a de transferir conhecimento.

É preciso insistir: este saber necessário ao professor - que ensinar não é transferir conhecimento - não apenas precisa ser apreendido por ele e pelos educandos nas suas razões de ser - ontológica, política, ética, epistemológica, pedagógica, mas também precisa ser constantemente testemunhado, vivido. (FREIRE, 1999:52)
\end{abstract}

Assim, ensinar está diretamente relacionado a construir. Envolve questões políticas, éticas, sociais. Aprender a aprender para depois ensinar a aprender.

Precisamos rever as posturas de educadores que individualizam saberes. Necessitamos de posicionamentos críticos fundamentados, e não de palavras soltas e desmotivadoras, para colocarmos em prática a transversalidade. A respeito da crítica, Freire (2000:59) diz que: "É preciso aceitar a crítica séria, fundada, que recebemos, de um lado, como essencial ao avanço da prática e da reflexão teórica, de outro, ao crescimento necessário do sujeito criticado".

Consideramos possuir despreparo e desconhecimento dos temas transversais aqueles que afirmam serem alguns assuntos como a sexualidade, o meio ambiente, a ética, dentre outros, específicos de disciplinas.

Não há como negar que o que existe é a ausência de leituras e treinamentos dos professores para tratar dessas questões em sala de aula. Assim, deparamo-nos com a questão da formação do professor, que deve ser contínua, uma vez que as rápidas transformações sociais exigem deste um posicionamento mais político. Os alunos instigam-nos com temas que envolvem a transversalidade e, diante desses temas, costumamos adiar discussões. É urgente admitirmos esse despreparo. Acreditamos que a solução seria a constante indagação: há reflexão na prática docente? 


\section{REFERÊNCIAS}

AMORIM, M. S. S. (2007). Cidadania e participação democrática. Anais do II Seminário Nacional. Movimentos Sociais, Participação e Democracia. 25 a 27 de abril de 2007, UFSC, Florianópolis, Brasil

Brasil. Secretaria de Educação Fundamental. (1998). Parâmetros curriculares nacionais:apresentação dos temas transversais, ética / Secretaria de Educação Fundamental. - Brasília : MEC/SEF.

146p.

FREIRE, P. (1999). Pedagogia da autonomia: saberes necessários à prática educativa. Paz e Terra: São Paulo. . (2000). Política e Educação: ensaios. 4aed.São Paulo: Cortez.

GADOTTI, M. (1998). Pedagogia da práxis. 2. ${ }^{a}$ ed., São Paulo: Cortez.

GARCIA, L. A. M. Transversalidade e Interdisciplinaridade. Disponível em: http://4pilares.net/text-cont/garcia-transversalidade-print.htm\#LG. Acesso em 07/09/10. [s.d., s.p].

MORIN, E. (2001). Os sete saberes necessários à educação do futuro. 3. a ed., São Paulo: Cortez.

RUIZ, M. J. F. (2003) O papel social do professor: uma contribuição da filosofia da educação e do pensamento freireano à formação do professor. REVISTA IBEROAMERICANA DE EDUCACIÓN. N 33, pp. 55-70.

ZABALA, A. (1998). A prática educativa: como ensinar. Porto Alegre: Artmed.

\section{A AUTORA}

Érica Pires Conde é licenciada em Letras (Português) pela Universidade Estadual do Piauí e em Pedagogia pela Universidade Paulista - UNIP; Mestre em Educação pela Universidade São Marcos - São Paulo, e em Linguística pela Universidade Federal do Ceará - UFC. Atualmente, é professora assistente da Universidade Federal do Piauí UFPI.

E-mail: ericaconde@uol.com.br 